\title{
DOENÇA RENAL: DETECÇÃO PRECOCE EM GRUPOS DE HIPERDIA
}

\author{
KIDNEY DISEASE: EARLY DETECTION IN HIPERDIA GROUPS
}

\author{
Fabiana Meneghetti Dallacosta, Natana Helen Belotto Masson, Daniela Cristiane da Silva \\ Pasquali
}

Universidade do Oeste de Santa Catarina - UNOESC

\begin{abstract}
This research is part of the Renal Project that aimed to diagnose early stage of kidney disease in the Hiperdia groups of 10 cities in the Midwest of Santa Catarina. A total of 1,486 people participated in the project, of which 448 collected a urine test for proteinuria analysis, and made up the sample from this study. Of the 448 diabetic and hypertensive participants, $64.5 \%$ were female, mean age $63.1 \pm 12$ years, $21.8 \%$ diabetics, $83.9 \%$ hypertensives, and 5.8\% presented both pathologies.. One hundred and ten people (24.5\%) had Glomerular Filtration Rate lower than $60 \mathrm{ml} / \mathrm{min}$ and proteinuria was identified in 70 people (15.6\%). Creatinine and urea values showed an inverse correlation with GFR. The high number of people with GFR below 60 and the number of people with proteinuria confirms the importance of early detection, especially in the risk groups, as well as the guidance and monitoring of hypertensive and diabetic patients, focusing on prevention and health promotion.
\end{abstract}

Key words: Early diagnosis. Hypertension. Diabetes Mellitus. Kidney Diseases.

\section{Resumo}

Esta pesquisa faz parte do Projeto Renal que teve por objetivo diagnosticar a doença renal em estágio inicial nos grupos de Hiperdia de dez municípios do Meio Oeste de Santa Catarina. Participaram do projeto 1.486 pessoas, sendo que 448 coletaram exame de urina para análise de proteinúria, e compõe a amostra deste estudo. Dos 448 diabéticos e hipertensos participantes, $64,5 \%$ são do sexo feminino, média de idade $63,1 \pm 12$ anos, $21,8 \%$ diabéticos, $83,9 \%$ hipertensos, sendo que 5,8\% apresentavam as duas patologias. Centro e dez pessoas (24,5\%) estavam com a Taxa de Filtração Glomerular inferior a $60 \mathrm{ml} / \mathrm{min}$ e a proteinúria foi identificada em 70 pessoas (15,6\%). Valores de creatinina e ureia apresentaram correlação inversa com a TFG. O elevado número de pessoas com TFG abaixo de 60 e o número de pessoas com proteinuria confirma a importância da deteç̧ão precoce, principalmente nos grupos de risco, além da orientação e acompanhamento dos hipertensos e diabéticos, com foco na prevenção e promoção da saúde.

Palavras chave: diagnóstico precoce. Hipertensão. Diabetes Mellitus. Nefropatias. 


\section{Introdução}

A prevalência da Doença Renal Crônica (DRC) vem crescendo acentuadamente no Brasil, passando a assumir um sério problema de saúde pública. Existiam em 2010 aproximadamente 92.091 pacientes cadastrados em programas de diálise, já em 2014, representando um aumento de 20 mil pacientes, chegou-se ao número de 112.004 pacientes em diálise. Somente em 2014 cerca de 36.548 pacientes iniciaram tratamento no Brasil ${ }^{1}$.

Porém, não é um problema que apenas nosso país está enfrentando. Dados revelam que Japão e Formosa são os países que possuem as maiores prevalências de DRC em fase terminal, com cerca de 1.800 e 1.600 pacientes por cada milhão de habitantes respectivamente; já Estados Unidos e Espanha possuem números correspondentes a 1.500 e 1.000 pacientes por mil habitantes ${ }^{2}$.

Bastos et al $^{3}$ lamentam que não haja muitos estudos epidemiológicos e que orientem quais pessoas deveriam ser rastreadas para o devido tratamento precoce. Consequentemente, a falta de tratamento adequado acaba por refletir na perda da oportunidade da implementação de prevenção no modo primário, secundário e terciário, isso tudo devido à falta de conhecimento sobre a doença e a não utilização de testes simples para diagnóstico e avaliação funcional da função renal ${ }^{4}$.

Para intervir na progressão da doença, é necessário diagnosticá-la precocemente e programar medidas para estabilizar a função renal ou diminuir a queda da filtração glomerular, assim como reduzir as comorbidades que surgem junto com a falência renal $^{5}$.

Os casos em estágio inicial podem ser diagnosticados por testes laboratoriais simples, sendo importante para o início do tratamento adequado e a redução da progressão da doença, possibilitando a correção das complicações mais frequentes e ainda prevenindo a evolução precoce para o óbito. Dois testes simples que deveriam ser feitos, e que são fundamentais no diagnóstico, são a dosagem de creatinina, que pode também ser utilizada para a estimativa da filtração glomerular, e a pesquisa de proteinúria ${ }^{6}$.

É importante detectar em pacientes antes que estes desenvolvam a DRC e que apresentem filtração glomerular inferior a $60 \mathrm{~mL} / \mathrm{min}$, podendo deste modo evitar que a doença progrida ${ }^{7}$.

Hipertensão arterial sistêmica, Diabetes mellitus, idosos e pessoas com história familiar de nefropatia são os grupos que mais estão vulneráveis a desenvolver DRC. Estes, mesmo que assintomáticos, devem anualmente ser avaliados e realizar exame de urina, como uma triagem para prevenir e diagnosticar precocemente a $\mathrm{DRC}^{8}$.

As equipes que atuam na Estratégia Saúde da Família (ESF) tem papel fundamental neste processo, devendo atuar permanentemente na vigilância e detecção precoce da doença renal, mas o próprio sistema brasileiro de saúde só passou a investir nessas ações recentemente, e de forma incipiente ${ }^{2}$.

Este estudo teve por objetivo detectar a doença renal em estágio inicial em pessoas hipertensas e diabéticas, participantes de grupos Hiperdia no Meio Oeste de Santa Catarina.

\section{Metodologia}

Estudo quantitativo, realizado com hipertensos e diabéticos, de dez municípios do Meio Oeste de Santa Catarina. Este trabalho faz parte do Projeto Renal, realizado em 2016, em dez municípios, no qual foi realizado palestra em grupos Hiperdia e após os pacientes foram entrevistados e encaminhados para coleta de creatinina e exame de urina para detecção de proteinúria. Do projeto renal participaram 1.486 pessoas, sendo que 448 coletaram exame de urina para análise de proteinúria, e compõe a população deste estudo, tendo sido excluídos todos que não haviam realizado o exame de urina.

Para análise da relação entre as variáveis categóricas foi utilizado o Coeficiente de Correlação de Pearson, e o teste do Quiquadrado. Para as variáveis quantitativas foi utilizado o Teste $T$ de Student. Foi adotado nível de significância quando $p<0,05$. As pessoas com TFG $<60 \mathrm{ml} / \mathrm{min}$ foram consideradas com provável Doença Renal Crônica (DRC).

A pesquisa foi aprovada pelo Comitê de Ética em Pesquisa da Universidade do Oeste de Santa Catarina, com o parecer número 160.925, e todos os participantes assinaram o Termo de Consentimento Livre e Esclarecido.

\section{Resultados e discussões}

Dos 448 hipertensos e diabéticos incluídos no estudo, a média de idade foi de $63,1 \pm 12,0$ anos, 289 (64,5\%) do sexo feminino e 159 $(35,5 \%)$ do sexo masculino, 98 (21,9\%) são diabéticos, $376(83,9 \%)$ são hipertensos, sendo que $26(5,8 \%)$ possuem as duas patologias associadas. 
A proteinúria neste estudo foi identificada em 70 pessoas $(15,6 \%)$, todos na categoria $A 1$ $(<30 \mathrm{mg} / \mathrm{g})$. Indivíduos normais excretam pequenas quantidades de proteína na urina, considerada fisiológica, entretanto, excreção em quantidades elevadas é marcador sensível de DRC secundária a diabetes, glomerulopatias primárias e secundárias e hipertensão arterial ${ }^{5}$. Destaca-se a importância de repetir o exame de proteinúria, a fim de confirmar e quantificar a perda de proteína, sendo considerado como referência o exame de urina de 24 horas, e salientando-se que pacientes com albuminúria persistente são considerados com DRC ${ }^{9}$.

Analisando a TFG, 110 pessoas (24,6\%) estão com taxa de filtração inferior a $60 \mathrm{ml} / \mathrm{min}$, o que os coloca em grande risco de já estar com DRC em estágio inicial. Estudo realizado no sudeste do Brasil, com hipertensos e diabéticos, também encontrou $24,6 \%$ com TFG inferior a $60 \mathrm{ml} / \mathrm{min}^{10}$.

A adequada mensuração da função renal é imprescindível para realizar o diagnóstico e tratamento de doenças renais, calcular doses adequadas de medicações, definir prognósticos, interpretar possíveis sintomas urêmicos e, se for o caso, escolher a terapia renal substutiva ${ }^{11}$. Mesmo o paciente não apresentando sintomas, é importante estimar a TFG para a detecção em fase inicial da doença, favorecendo as ações preventivas, para isso, deve-se ter um certo nível se suspeição acerca da doença, principalmente em pacientes que já apresentam fatores de risco para a $\mathrm{DRC}^{12}$.

$A$ idade apresentou forte correlação inversa com a TFG $(r=-0,6 ; p=0,00)$, e as pessoas acima de 60 anos tiveram mais perda de proteína na urina $(p=0,00)$. Os valores de creatinina e ureia também demonstraram que aumentam conforme aumenta a idade $(r=-0,2 ; p=0,00$ para ambos). A função renal pode estar reduzida em pacientes idosos, fazendo parte do próprio processo de envelhecimento de seu organismo. Por este fato, pode ser difícil distinguir a diminuição da função renal decorrente da idade com àquela relacionada à DRC. Sendo assim, o diagnóstico não deve ser realizado apenas a partir da estimativa da função renal, mas também por outros marcadores, como alteração do sedimento urinário ${ }^{13}$.

As alterações anatômicas e fisiológicas dos rins constituem um agravante para DRC em idosos, tornando-os mais suscetíveis à disfunção renal com o decorrer dos anos, isso tudo devido ao processo de envelhecimento renal. Idosos com idade próxima aos 80 anos possuem sua função renal limitada pela metade e, se acometido por alguma patologia renal, podem progredir para a Insuficiência Renal Crônica, que é bastante comum ${ }^{14}$.

Os valores de creatinina $(r=-0,5 ; p=0,00)$ e uréia $(r=-0,3 ; p=0,00)$ apresentaram correlação inversa com a TFG, corroborando com a literatura de que quanto maiores os valores de creatinina e uréia, menor a TFG. Ainda que amplamente utilizada, a creatinina não tem relação inversa direta com a TFG, sendo que a creatinina só aumentará após a TFG ter decaído para cerca de $50 \%-60 \%$ de seu nível normal ${ }^{15}$. Os valores de referência da creatinina variam de acordo com a massa muscular de cada indivíduo, já que esta é derivada da creatina dos músculos, sendo, desta forma, diferentes para crianças, mulheres e homens adultos ${ }^{11}$. A uréia também está sujeita à mudanças por razões não relacionadas com a TFG ${ }^{15}$.

A detecção precoce da DRC aborda a identificação e tratamento das causas reversíveis; o diagnóstico e intervenção de fatores que retardam a função renal; a estabilização da TFG; a identificação e a reparação de grandes complicações e as morbidades mais prevalentes na DRC; e a obtenção de melhores parâmetros bioquímicos, psicológicos e físicos no início da $\mathrm{TRS}^{15}$. À atenção primária se atribui a função da abordagem do paciente, identificando os grupos de risco, realizando diagnóstico precoce, o tratamento da patologia em seu estágio inicial e também o encaminhamento para especialista, sendo que existe uma escassez de ações dirigidas à detecção precoce voltada à DRC neste âmbito de atenção primária ${ }^{16}$.

Classificando as formas de abordagem do doente renal de acordo com suas devidas funções e dimensionamento, considera-se que a prevenção da DRC deve ser exclusivamente realizada pelo ESF por meio da identificação dos fatores de risco e intervenção dos mesmos; ao nível secundário podem ser desempenhadas pelo ESF e o nefrologista, de modo a retardar a progressão da patologia, identificar e corrigir suas complicações e comorbidades; e já ao nível terciário cabe a identificação e manuseio das complicações mais frequentes, realizados pelos nefrologistas ${ }^{12}$.

Todavia, o encaminhamento secundário tem se evidenciado tardiamente, podendo estar relacionada a falta de conhecimento da epidemiologia da patologia, dos critérios diagnósticos e dos cuidados nos estágios iniciais da doença. A detecção precoce é importante para a abordagem e execução de ações educativas que visam uma qualidade de vida melhor ao paciente e também capacita-o para o 
seu autocuidado ${ }^{16}$.

Faz-se necessário que o paciente com DRC seja acompanhado por uma equipe multiprofissional, a qual oriente e ajude quanto ao aconselhamento acerca da mudança do estilo de vida, avaliação nutricional, orientação sobre exercícios físicos, abandono do tabagismo, orientação sobre vacinação, estimulação do uso correto das medicações, educação continuada sobre a DRC, estimular o autocuidado, orientar sobre as modalidades de tratamento da DRC, entre outros ${ }^{17}$.

É importante que a atenção primária implante em suas unidades o combate ao tabagismo, alcoolismo, obesidade e o sedentarismo para prevenir a DRC, e intervenha para que a doença não progrida, além de controlar rigorosamente o diabetes, a hipertensão e investigar a função renal, principalmente dos grupos de risco ${ }^{16}$.

\section{Conclusão}

Compuseram deste estudo 448 participantes de grupos HiperDia de cidades do Meio Oeste de Santa Catarina, a maioria mulheres, com idade média de 63,1 anos, 83,9\% hipertensose $21,9 \%$ diabeticos.

O número elevado de pessoas com filtração glomerular reduzida demonstra a importância deste tema, visto que a falta de estratégias que detectem precocemente a doença e possibilitem o diagnóstico na fase inicial, retardam o tratamento, assim, faz-se necessário a implantação de medidas visando à educação da população de risco, tais como açõesde promoção da saúde e acompanhamento periódico de hipertensos e diabéticos a fim de reduzir os índices de falência renal.

Cabe as equipes das ESFs criar e divulgar políticas e campanhas que compreendam também as pessoas ainda não doentes, com intuito de alertá-las sobre os fatores de risco, tendo por objetivo a mudança no estilo de vida e, com isso, reduzir e evitar a incidência de doenças que possam levar a DRC. As equipes, por sua vez, também precisam de treinamento e educação permanente atuante, incluindo as doenças renais na sua formação continuada.

O estudo teve algumas limitações quanto ao número de pessoas participantes e a disponibilidade de estarem realizando exame de proteinúria. Faz-se necessário acompanhamento destes pacientes, a fim de confirmar ou não a presença de DRC, realizando exames confirmatórios conforme rotina da unidade.

A doença renal tem elevada prevalência e é diagnosticada tardiamente, espera-se que estudos como este fortaleçam as ações preventivas e educativas na atenção básica, e que a equipe de saúde mantenha-se vigilante na detecção precoce da doença renal.

\section{Referências}

1. Sesso RC, et al. Inquérito brasileiro de diálise crônica 2014. J Bras Nefrol. 2016; (38)1: $54-61$.

2. Lugon JR. Doença renal crônica no Brasil: um problema de saúde pública. J Bras Nefrol. 2009; (31)1: 2-5.

3. Bastos MG, et al. Doença renal crônica: problemas e soluções. J Bras Nefrol. 2004, (26)4: 202-215.

4. Bastos MG, Bregman R, Kirsztajn GM. Doença renal crônica: frequente e grave, mas também prevenível e tratável. Rev Assoc Med Bras. 2010; 56(2): 248-53. Disponível em: http://www.scielo.br/pdf/ramb/v56n2/a28v56n2 .pdf.

5. Kirztajn GM, Bastos MG. Proposta de padronização de um programa de rastreamento da doença renal crônica. J Bras Nefrol. 2007, (29)1: 18-22.

6. Kirztajn GM, Bastos MG, Andriolo A. Dia mundial do rim 2011, Proteinúria e creatinina sérica: testes essenciais para diagnóstico de doença renal crônica. Jornal Bras. Patol. 2011, (47)2: 100-103.

7. Silva MMH, Brune MFSS. Importância do cálculo da taxa de filtração glomerular na avaliação da função renal de adultos. Rev Bras Farm. 2011, (92)3: 160-165. Disponível em: http://rbfarma.org.br/files/rbf-2011-92-3-13.pdf. 8. Pena PFA, et al. Cuidado ao paciente com doença renal crônica no nível primário: pensando a integridade e o matriciamento. Ciência e saúde col. 2012, (17) 11: 3135-3144. Disponível em: http://www.redalyc.org/html/630/63024420029 /.

9. Kirstajn GM, Salgado Filho Natalino, Draibe AS, Padua Netto MV, Thomé FS, Souza E, Bastos MG. Leitura rápida do KDIGO 2012: diretrizes para avaliação e manuseio da doença renal crônica na prática clínica. J Bras Nefrol. 2014, (36)1: 63-73.

10. Alves LF, et al. Prevalence of chronic kidney disease in a city of southeast Brazil. Braz J Nephrol. 2017, (39)2: 126-34.

11. Kirstajn GM. Avaliação do ritmo de filtração glomerular. J Bras. Patol Med Lab. 2007, (43)4: 257-264. Disponível em: 
http://www.scielo.br/scielo.php?script=sci_artte $x t \& p i d=S 1676-24442007000400007$.

12. Travagim DAS, et al. Prevenção da doença renal crônica: intervenção na prática assistencial em uma equipe de saúde da família. Rev enferm online. 2016, (10)9: 3361-3368.

13. Pecoits Filho R. Diagnóstico de doença renal crônica: avaliação da função renal. J Bras Nefrol. 2004, (26)3: 4-6.

14. Kusumota L, Rodrigues RAP, Marques S. Idosos com insuficiência renal crônica: alteração do estado de saúde. Rev Latino-Am Enferm. 2004, (12)3: 525-532. Disponível em: http://dms.ufpel.edu.br/ares/bitstream/handle/ 123456789/160/v12n3a11.pdf?sequence=1.

15. Bastos MG, Kirztajn GM. Doença renal crônica: importância do diagnóstico precoce, encaminhamento imediato e abordagem interdisciplinar estruturada para melhora do desfecho em pacientes ainda não submetidos à diálise. J Bras Nefrol. 2011, (33)1: 93-108.

16. Santos JRFM, et al. Estratégias da atenção básica na doença renal crônica: a importância do diagnóstico precoce. Rev saúde.com. 2017, (13)2: 863-870.

17. Brasil. Ministério da Saúde. Secretaria de Atenção à Saúde. Departamento de Atenção Especializada e Temática. Diretrizes Clínicas para o Cuidado ao paciente com Doença Renal Crônica - DRC no Sistema Único de Saúde. Brasília, 2014.

\section{Endereço para Correspondência}

Universidade do Oeste de Santa Catarina UNOESC

R. Getúlio Vargas, 2125, Joaçaba - SC

CEP.: 89600-000

e-mail: fabiana.dallacosta@unoesc.edu.br

Recebido em 19/10/2017

Aprovado em 07/06/2018

Publicado em 30/06/2018 